\title{
Report of the Editors
}

\author{
Robert M. Kunst ${ }^{1}$
}

Published online: 29 December 2018

(c) Springer-Verlag GmbH Germany, part of Springer Nature 2018

\section{Submissions}

With pleasure I can report that the number of new submissions to Empirical Economics has steadily increased over the last years. In 2018 we have definitely surpassed the mark of 1000 submissions. The editorial continues to be committed to quality, so rather than increasing the number of published papers unduly, a slightly increasing proportion of submissions have to be rejected. By some extrapolation of the handling of already submitted manuscripts, we estimate the current rejection rate at more than $85 \%$.

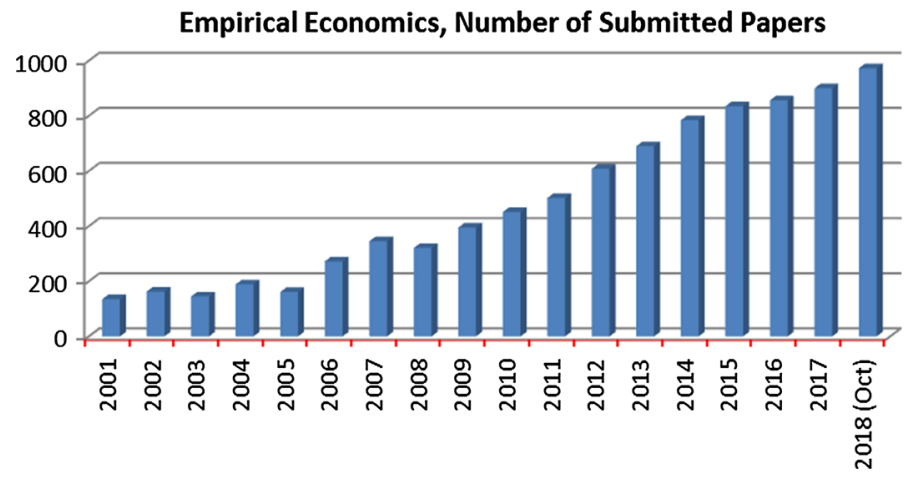

\section{Special Issues}

2018 has seen the topical issue "Special Issue on Spatial Econometrics in Honor of Ingmar Prucha” published by Badi H. Baltagi, Giuseppe Arbia, and Harry Kelejian. Martin Wagner and I are already working on editing the next special issue on

Robert M. Kunst

kunst@ihs.ac.at

1 Institute for Advanced Studies Vienna, Josefstadter Strasse 39, 1080 Vienna, Austria 
"Economic Forecasting". On average, the editorial intends to publish one special issue per year.

\section{Board of Editors}

The last year has seen several major changes in our editorial board. After a long career as one of our editors, Badi H. Baltagi has decided to retire from the journal's editorial team by the end of 2018. There is hardly any editor in the journal's recent history whose significance can be compared to Badi's. It was under Badi's guidance that the journal has evolved from a minor outlet with primarily regional significance to a global player. Badi has also organized and edited many special issues with various co-editors on diverse topics. It was a pleasure to work with Badi, and I would like to extend my sincerest thanks and appreciation for his services to the journal.

Conversely, I can announce that Joakim Westerlund could be convinced to join the editorial team of Empirical Economics. Joakim has been a valuable Associate Editor for Empirical Economics for several years. Professor Westerlund holds a chair of economics at the University of Lund, and his research focuses on panel-data econometrics.

Several new Associate Editors could be added to the list in 2018, among them Charles Bellemare, Markus Eberhardt, Christoph Hanck, Emil Malikov, Hans Manner, Camilla Mastromarco, Luis Orea, Ekaterini Panopoulou, Hans-Martin von Gaudecker, whereas others have left us after serving the journal well for some time spans. We particularly regret that Erik Biorn has passed away in 2018.

Acknowledgements My special gratitude is extended to my fellow editors and each member on the editorial board for their work and dedication to the journal. Particularly, I thank Liane Wolf for a lifetime of serving the journal as Editorial Assistant. Liane was succeeded by Sedat Demir in early 2018. Furthermore, I wish to express my appreciation on behalf of the entire editorial team to the numerous referees who have provided us with reports in their fields of expertise on submissions in the recent years.

Publisher's Note Springer Nature remains neutral with regard to jurisdictional claims in published maps and institutional affiliations. 